\title{
Design Considerations of Heat Guides Fabricated using Additive Manufacturing for Enhanced Heat Transfer in Electrical Machines
}

\author{
Rafal Wrobel \\ School of Engineering, Newcastle University \\ Newcastle upon Tyne, UK \\ rafal.wrobel@newcastle.ac.uk
}

\author{
Ahmed Hussein \\ HiETA Technologies Ltd. \\ Bristol, UK \\ ahmedhussein@hieta.biz
}

\begin{abstract}
This paper investigates a new heat extraction approach in application to the high-specific-output electrical machines. The proposed technique employs thermally conductive heat guides (HGs) to provide supplementary heat evacuation paths for the machine regions, which are particularly susceptible to high power loss. Here, the research focus has been placed on the statorwinding assembly. The HGs investigated in this work rely solely on conductive heat transfer, in contrast to the solutions involving working fluid phase change, e.g. heat pipes (HPs). It is intended for the HGs to be an integral part of the stator-winding assembly, e.g. HGs incorporated in the winding active and/or end region. Such arrangement however, imposes several design challenges. These are related with the HGs being a source of additional power loss due to the machine's magnetic flux leakage. The objective of this study is to evaluate a concept of HGs, which are 'immune' to the external magnetic field with 'good' heat transfer capability. To facilitate that, a combination of detailed multi-physics designoptimization together with modern additive manufacturing, i.e. selective laser melting (SLM) method, has been employed here. The theoretical analysis has been supplemented with experimental body of work. A number of stator-winding hardware exemplars (motorettes) incorporating alternative HGs designs have been fabricated and tested. The research findings show that the optimised HGs allow for $30 \%$ improvement in dissipative heat transfer from the winding body and insignificant additional power loss, for the analysed stator-winding assembly.
\end{abstract}

Keywords - heat guides, heat transfer, power loss, statorwinding assembly, electrical machines, additive manufacturing

\section{INTRODUCTION}

When designing a new high-specific-output electrical machine, the balance between the generated power loss and dissipative heat transfer needs to be carefully considered. The effective thermal management is here one of the key enabling factors [1]-[10]. Numerous examples of evacuating heat from electrical machines include the passive and active methods [4]. In both cases, the generated heat is commonly extracted through the machine's external periphery. In specific applications, the generated heat is extracted directly from the heat sources by contact with a coolant, i.e. direct gas or liquid heat evacuation [4]. The latter approach usually involves a more complicated machine design, which incorporates functionality of the thermal management system. On the other hand, the simpler heat extraction from the machine's housing requires some form of 'heat guiding' to enhance heat transfer from across multiple materials and subassemblies. For example, the stator-winding assemblies are commonly impregnated using 'high' thermal conductivity materials or some other design features are introduced to improve the dissipative heat transfer [1]-[10]. However, such commonly used techniques are frequently limited by various factors like the physical properties of impregnating materials, fabrication methods, or cost associated with practical implementation for in-volume manufacture among others.

In this feasibility study a new heat extraction method, in application to electrical machines, is proposed. The technique employs thermally conductive heat guides (HGs) to provide supplementary heat evacuation paths to the machine regions, which are particularly prone to high power loss. The HGs can be manufactured as passive or active components. The passive guides rely solely on conductive heat transfer, whereas the active designs additionally employ materials with phase change, e.g. heat pipes (HPs). This investigation focuses on heat evacuation from the stator-winding assembly, which is usually attributed with the main heat source in electrical machines. The passive HGs only, are analysed in this study. It is important to note that the use of active components like HPs, to improve heat management in electrical machines, have been reported in the literature [1], [3]. Also, some other forms of 'heat guiding' have been investigated by other authors [4]. However, practical implementation of any of the HG solutions require careful considerations.

The proposed HGs, are intended here to be an integral part of the stator-winding assembly and are mounted in the near proximity of winding. For example, HGs placed within the stator slots to enhance heat transfer from the winding's active length and/or HGs located by the winding's ends to improve heat extraction from the machine end-regions. Clearly, any electrically conductive parts placed near the winding body will be exposed to the time and spatial variation of magnetic flux leakage, and consequently such components will generate additional power loss. Therefore, the use of 'solid' metallic HGs would provide negligible improvement, if any, to the overall system performance. In particular, when considering high-speed/high-frequency machine designs. It is important to 
note here that the thermal and electrical conductivities of metallic materials are closely related and a 'good' thermal conductor has also 'good' electrical properties. This imposes clear design challenges for HGs, where the enhanced heat transfer and additional power loss need to be well balanced.

The initial results have shown that a combination of detailed multi-physic design-optimisation and modern additive manufacturing enables HG solutions with minimal additional power loss. Here, selective laser melting (SLM), a laser-driven metal powder-bed version of additive manufacturing has been used. The SLM allows fabrication of complex and optimised heat sink features that otherwise would be difficult to make using conventional manufacturing techniques. A HG, which is 'immune' to the external magnetic field with 'good' heat transfer capability would be very desirable. The main objective of this work is to assess feasibility of such HG concept, in the context of the next generation of high-specific-output electrical machines. The theoretical body of work has been supplemented here with experiments on a set of hardware exemplars. The results show that the optimised HGs allow for $30 \%$ improvement in dissipative heat transfer from the winding body and insignificant additional power loss, for the analysed statorwinding assembly.

\section{HARDWARE EXEMPLARS}

Fig. 1a) presents an outline of the stator-winding assembly incorporating HGs, which are placed in the stator slots for extracting heat from the winding's active length. The statorwinding is representative of a permanent magnet (PM) machine (rated power, $80 \mathrm{~kW}$ and rated rotational speed, 7,500 rpm). The stator is laminated using electrical steel (M250-35A), and the double-layer precision wound concentrated winding uses copper round-profile conductors with class $\mathrm{H}\left(180^{\circ} \mathrm{C}\right)$ enamel coating. A slot liner material (PEEK) is used to provide an electrical separation between the stator core pack and conductors, and HGs and conductors. The complete stator-winding assembly is encapsulated using 'high' thermal conductivity epoxy resin (Epoxylite EIP4260) to assure 'good' heat transfer from the stator-winding assembly to the machine housing, which is actively cooled $\left(60^{\circ} \mathrm{C}\right)$.

A 'reduced' stator-winding assembly sector (motorette) with a single coil and the neighbouring stator tooth-segments has

a)

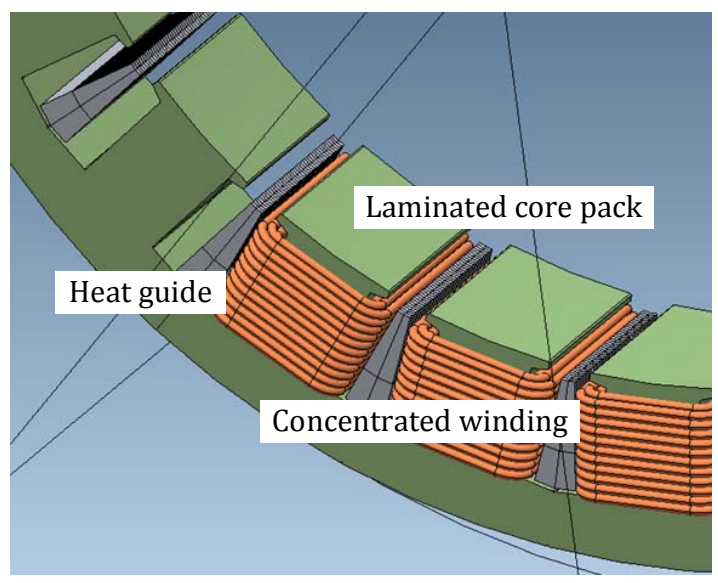

b)

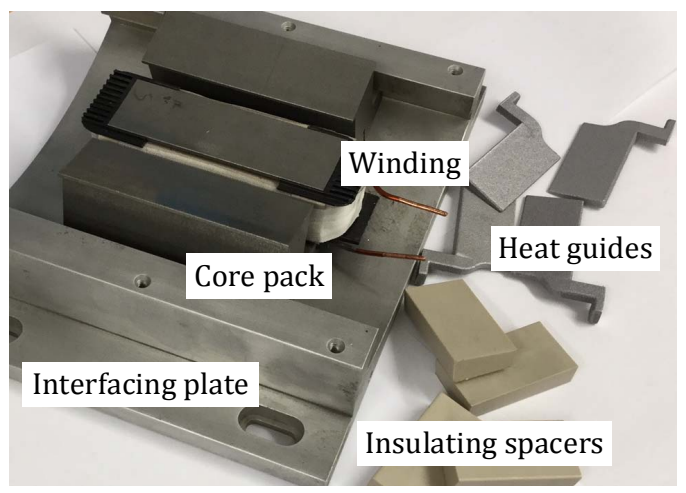

Fig. 1. Outline of the stator-winding assembly a) concept of the statorwinding with $\mathrm{HGs}$ placed in the stator slots - 3D FE model representation, b) motorette hardware prior to final assembly and impregnation

been chosen for experimental work in this feasibility study. Such setup provides the exact slot geometrical representation as for the complete stator-winding assembly. This is essentials when analysing the power loss components [7]-[9]. The motorette hardware evaluation has been selected here to reduce cost and time associated with the prototyping and testing of alternative design solutions [5]- [9]. Fig. 1b) presents a motorette exemplar together with constituent components prior to final assembly and impregnation. The core pack assembly is heat shrunk into the aluminium interfacing plate to provide 'good' contact between the parts. The HGs shown in Fig. 1b) are made of aluminium alloy (AlSi10Mg). The individual HGs are inserted in the slots (two per slot) and then securely mounted to the interfacing plate. It is important to note that only a half of the HG width across the stator slot is required for the motorette experimentation.

To emulate adiabatic boundary condition between neighbouring coils, i.e. no heat transfer across individual coils, a set of insulating blocks (PEEK) are placed in the slot cavities for the remaining coils. A single motorette is instrumented with several type-K thermocouples placed in the winding active and end regions, and stator core pack (back iron and tooth body). Such constructed hardware exemplars allow for both thermal and power loss analysis and are sufficient to inform 'low' additional power loss and enhanced heat transfer HG design [5][10]. However, the motorette hardware does not provide complete insight into the power loss generated in the winding at ac operation, as the contribution of neighbouring phases to the overall loss is not accounted for [7]. Also, the rotational ac effects are not considered here. These however, can be evaluated theoretically for the complete stator-winding using a finite element analysis (FEA) [7]-[9], some which are discussed later in the paper.

Fig. 2 presents six alternative HG designs considered in the study. These have been selected based on the theoretical analysis, details of which are presented in the following sections of the paper. The heat guide variants (HGVs) include: solid construction (HGV1), laminated construction (HGV2-HGV3) and lattice construction (HGV4-HGV6). The motorette design without HGs in place is used here as a baseline for benchmarking both power loss and heat transfer performance measures. 


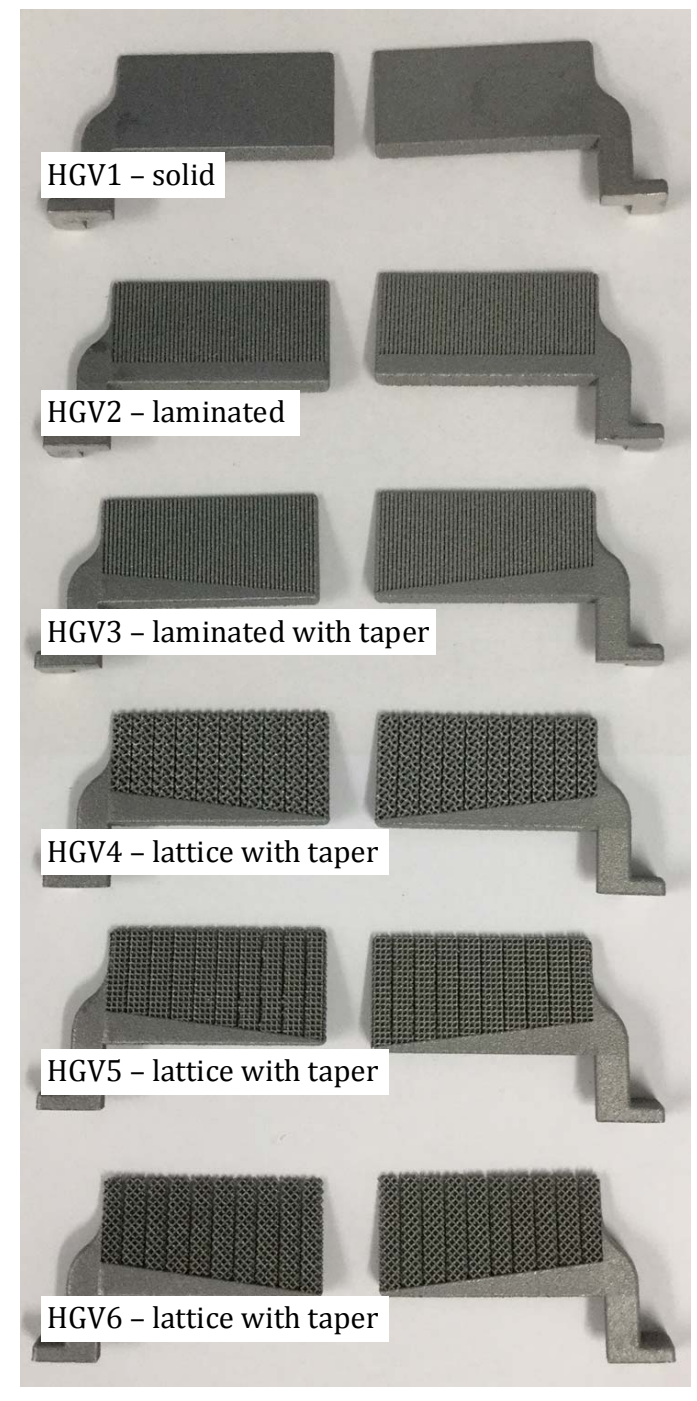

Fig. 2. Alternative HG designs

\section{THEORETICAL ANALYSIS}

To enable a HG design combining 'good' heat transfer and 'low' additional power loss, a detailed analysis combining both electromagnetic and thermal effects is required. In this feasibility study, a three-dimensional (3D) FE approach have been employed in the design process. Clearly, the requirements for the HG design are conflicting when considering 'solid' metallic materials. A metallic material with 'good' thermal conductivity has usually 'good' electrical conductivity, which will most likely lead to additional machine power loss at ac operation. Here, a design concept utilising an appropriate lamination, assuring 'poor' equivalent electrical conductivity, but 'good' equivalent thermal conductivity is investigated. By the use of appropriate fabrication, the equivalent electrical and thermal properties of the HG become anisotropic. The material properties for selected axes of the HG are altered to provide 'good' heat transfer and 'low' power loss simultaneously. The theoretical analysis presented in this paper is limited to a more conventional method of altering physical properties to achieve material anisotropy. An axial lamination of the HG's body is discussed here in detail, with the research findings feeding into alternative HG designs fully utilising SLM additive manufacturing.

\section{A. Power Loss Separation}
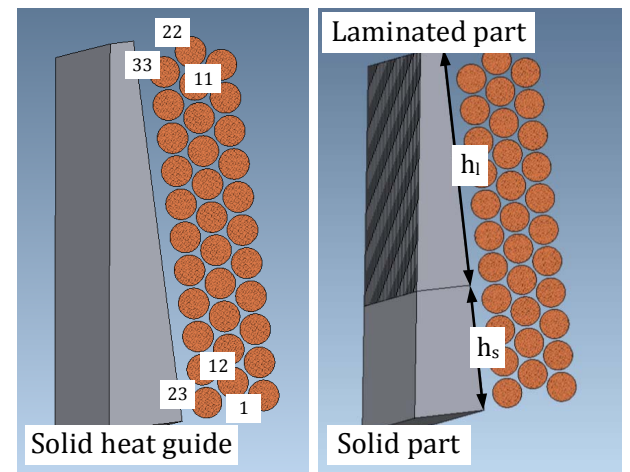

Fig. 3. Outline of the solid and partially laminated $\mathrm{HG}$ variants together with labels; here, the lamination thickness is fixed and equal to $1.0 \mathrm{~mm}$; conductor diameter is equal to $1.7 \mathrm{~mm}$

A detailed power loss analysis for the laminated $\mathrm{HG}$ concept has been performed. Here, a portion of the HG assembly is axially laminated to reduce the ac power loss due to the slot magnetic flux leakage. The solid spine of HG assures well defined heat transfer path to the heat sink. A number of alternative deign variants has been analysed, where the ratio of height of the laminated part to total HG height $\left(h_{l} /\left(h_{s}+h_{l}\right)\right)$ is altered, Fig. 3. The solid HG design represents here the worst case in terms of the additional power loss. It has been assumed that the HG is manufactured from aluminium alloy to ensure 'good' heat transfer and 'low' weight design. Two HGs, which are inserted into the slot from opposite ends of the statorwinding assembly, are used per a single slot.

All power loss components including the winding's individual conductors, stator core and $\mathrm{HG}$ for ac sinewave current excitation and fundamental frequency range up to $1 \mathrm{kHz}$ are accounted for. The temperature variation of the ac power loss is also considered. The 3D FE model representation of the statorwinding incorporating HG is schematically shown in Fig. 1a). It is important to note that Fig. 1a) presents model of the complete stator-winding assembly accounting for neighbouring phases and multiple HGs. The motorette analysis discussed in this section uses simpler model definition with a single coil/phase and half-width HGs. Both, HGs and the individual winding's conductors are defined as 'solid conductors' in the FEA. The model regions representing conductors are configured using an appropriate external circuit to form required electrical connections. Here, all conductors within a single coil are connected in series, whereas the winding phases are 'star' connected, where appropriate. The magnetic non-linearity of the core material is also accounted for. However, for the statorwinding or motorette analysis the magnetic saturation is of lesser importance as compared to the complete machine assembly, were the core pack operates at higher magnitude of the magnetic flux excursion.

As expected, the change of magnetic flux leakage is the most severe in the slot opening region. Consequently, the ac power loss contribution of the stator-winding assembly parts 


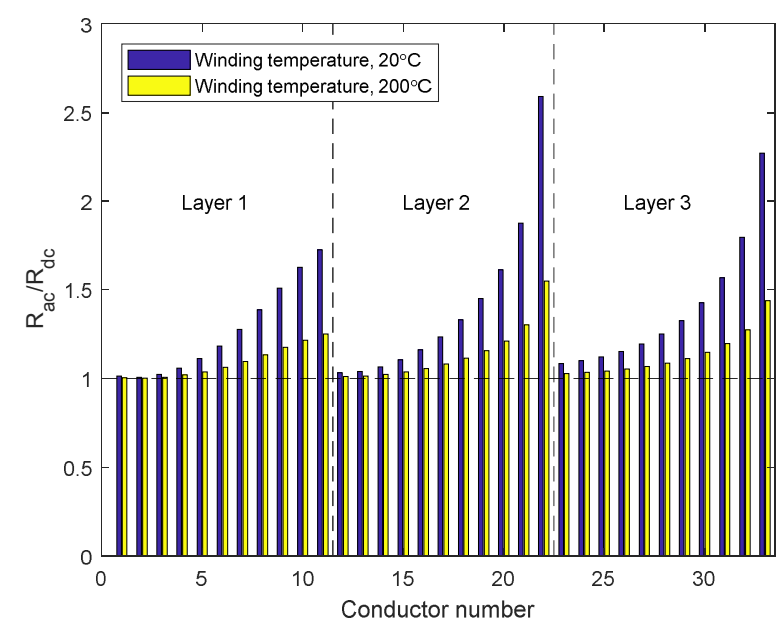

Fig. 4. Winding $R_{a c} / R_{d c}$ at reference sinewave current excitation, $1 \mathrm{kHz}$ fundamental frequency $(f)$ for motorette without HG assembly; here, the excitation current is equivalent to $4.5 \mathrm{~A}_{\mathrm{rms}} / \mathrm{mm}^{2}$ per conductor dc

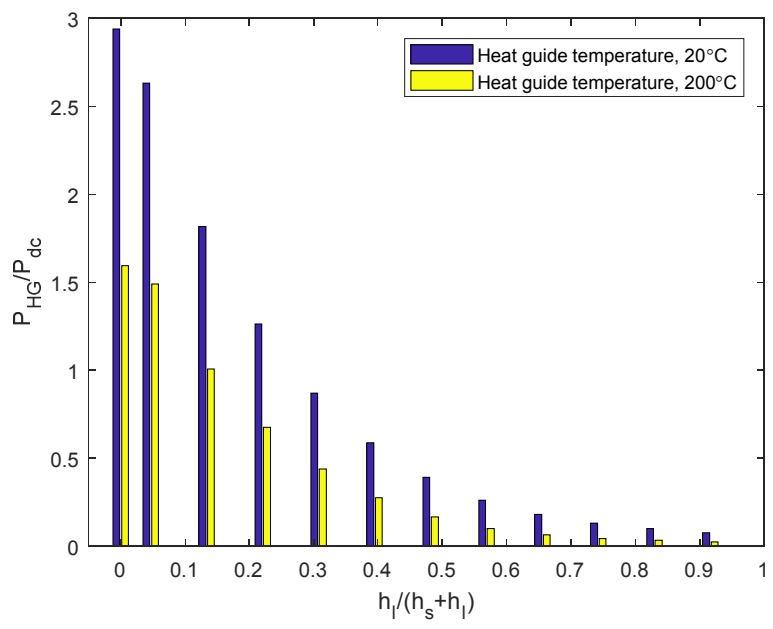

Fig. 5. Ratio of the additional $\mathrm{HG}$ power loss at ac operation to the dc winding power loss at reference excitation sinewave current, $f=1 \mathrm{kHz}$

exposed to this portion of the magnetic flux leakage is the highest. Fig. 4 shows per conductor increase of the dc winding resistance at ac operation to illustrate that effect, where the conductor numbering indicate consecutive coil layers, i.e. layer 1: 1 to 11 , layer 2: 12 to 22 and layer 3: 23 to 33 . Similar trend can be observed when analysing ac power loss associated with the HG assembly, Fig. 5. Here, the HG power loss is normalised to the winding dc power loss showing that the additional power loss is prohibitively large for the HG variants with large portion of 'solid' assembly. $\left(h_{l} /\left(h_{s}+h_{l}\right)\right)=0$ represents 'solid' HG design, whereas $\left(h_{l} /\left(h_{s}+h_{l}\right)\right)=1$ indicates fully laminated alternative. Also, a strong impact of the HG temperature on the generated power loss is observed, with approximately $50 \%$ loss reduction when comparing calculated data for $20^{\circ} \mathrm{C}$ and $200^{\circ} \mathrm{C}$. The close relationship between the ac winding and $\mathrm{HG}$ power loss provides clear design directions for a 'low' power loss HG solution.

To accelerate thermal assessment of the HG design variants, a functional representation for the individual power loss components as a function of dc winding power loss has been derived. For example, the $\mathrm{HG}$ power loss as a function of $\mathrm{dc}$ winding power loss, excitation frequency and winding temperature can be written in the following form,

$$
\left.P_{H G}\right|_{T}=\left.I_{d c}^{2} R_{d c}\right|_{T_{0}} \frac{\left.\left(\frac{P_{H G}}{P_{d c}}\right)\right|_{T_{0}}}{\left(1+\alpha\left(T-T_{0}\right)\right)^{\beta}}
$$

where, $\left.I_{d c}^{2} R_{d c}\right|_{T_{0}}$ is the winding dc power loss at reference temperature $T_{0}$ (here, $T_{0}=20^{\circ} \mathrm{C}$ ), $P_{H G}$ is the $\mathrm{HG}$ power loss generated at ac operation, $\alpha$ is the temperature coefficient of electrical resistivity for the $\mathrm{HG}$ material (here, $\alpha=4.3 \times$ $10^{-3} 1 /{ }^{\circ} \mathrm{C}$ ) and $\beta$ is derived from curve fit to the $P_{H G}$ data at two temperatures, e.g. $T_{0}$ and maximum intended operating temperature.

The ratio $\left.\left(P_{H G} / P_{d c}\right)\right|_{T_{0}}$ needs to be derived just once for a set of frequencies, temperature $T_{0}$ and given reference $P_{d c}$, allowing then for the HG power loss to be derived at any input current. Similar functional representations were derived for both winding and core power loss components [7]-[11]. These however, are not included here due to conciseness of the paper. A complete set of the formulae allows to significantly speed up thermal analysis, where the generated power loss needs to be iteratively updated with temperature. This is particularly important for the winding and HG regions. Also, such form of expressing the individual power loss components allows for deriving operating thermal envelope of a complete machine or motorette as function of the excitation parameters, i.e. excitation current magnitude and frequency.

\section{B. Heat Transfer Assessment}

To evaluate thermal behaviour of the individual HG design variants, a number of supplementary thermal 3D FEAs have been performed. It is important to note that the intended heat transfer mechanism within the stator-winding assembly is due to conduction. The generated heat is conducted and dissipated in the liquid cooled, temperature controlled housing, which is emulated by an appropriate 'cold' plate for the motorette analysis. Also, the heat transfer mechanisms within the complete stator-winding and motorette assemblies are equivalent.

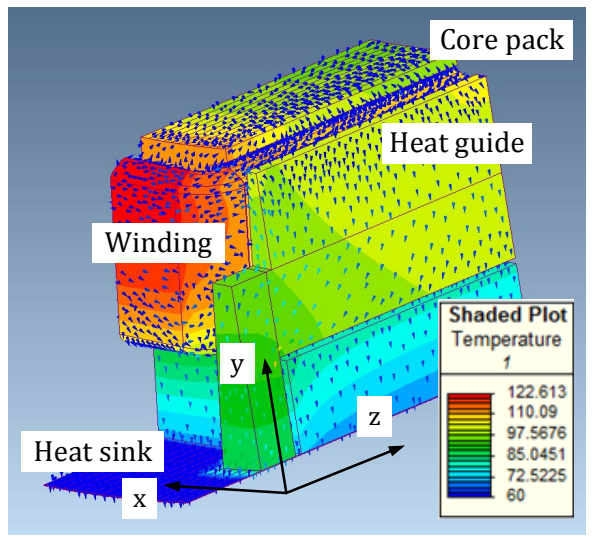

Fig. 6. An example temperature distribution and heat flux distribution for $\mathrm{dc}$ winding excitation; here, HG with $h_{l} /\left(h_{s}+h_{l}\right)=0.57$ and interfacing feature is shown; (temperature distribution in ${ }^{\circ} \mathrm{C}$ ) 
Fig. 6 presents thermal model representation of the statorwinding together with heat flux distribution. The encapsulating epoxy resin is not shown here. The winding is excited with dc current that is representative of dc thermal testing [5], [6]. For such operating condition, only dc winding power loss component is present, allowing for the stator-to-winding heat transfer to be accurately derived. A quarter of the stator tooth with a single coil is sufficient here to evaluate the thermal behaviour. It has been assumed that outer surface of the stator back iron is the only path for the generated heat to be evacuated. Here, a fixed temperature boundary condition of $60^{\circ} \mathrm{C}$ is set. The remaining surfaces of the model are adiabatically insulated. This represents the worst case scenario for a machine operation, where the other heat transfer mechanisms are not present, i.e. no heat transfer across the air-gap nor from the end-winding region due to convection or radiation. The contact thermal resistances have been initially assumed based on the authors' previous experience and available literature, by appropriately adjusting equivalent thermal conductivity for the contact regions, i.e. winding-to-stator or stator-to-housing interfacing layer. Here, the equivalent contact airgaps are equal to $10 \mu \mathrm{m}$ and $2.5 \mu \mathrm{m}$ for the winding-to-stator (slot liner) and stator-to-housing regions (thermal paste) [5], [14].

\section{TABLE I.}

THERMAL MATERIAL DATA

\begin{tabular}{lcc}
\hline Model region & {$\left[\mathrm{W} / \mathrm{m} \cdot{ }^{\circ} \mathrm{C}\right]$} & {$\left[\mathrm{J} / \mathrm{kg} \cdot{ }^{\circ} \mathrm{C}\right]$} \\
Winding & $k_{x}=k_{y}=3.5, k_{z}=229.3$ & 474 \\
Core pack & $k_{x}=k_{y}=22.2, k_{z}=4.9$ & 304 \\
HG (solid) & $k_{x}=k_{y}=k_{z}=230.0$ & 900 \\
HG (laminated) & $k_{x}=k_{y}=222.2, k_{z}=36.4$ & 908 \\
Epoxy resin & $k_{x}=k_{y}=k_{z}=0.85$ & 1700 \\
Slot liner ${ }^{2)}$ & $k_{x}=k_{y}=k_{z}=0.25$ & 1260 \\
Thermal paste ${ }^{3)}$ & $k_{x}=k_{y}=k_{z}=0.25$ & 1260 \\
\hline${ }^{1)}{\text { thermal properties for the winding active length; }{ }^{2)} 0.34 \mathrm{~W} / \mathrm{m}^{\circ}{ }^{\circ} \mathrm{C} \text { and }}^{3)}$ \\
$2.9 \mathrm{~W} / \mathrm{m}^{\circ} \cdot{ }^{\circ} \mathrm{C}$ before adjusting for the contact air-gaps
\end{tabular}

Table I includes complete list of thermal material data used in the analysis. The equivalent thermal conductivity for the impregnated winding, HGs and laminated core pack accounts for the regions anisotropy. Data for the winding and laminated core pack has been informed from tests on appropriate material samples [12].

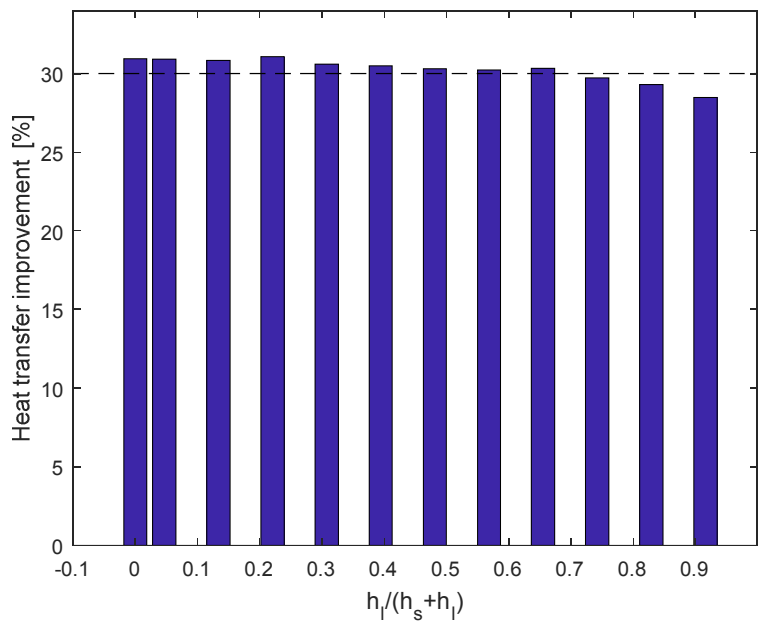

Fig. 7. Percentage improvement of the equivalent stator-to-winding heat transfer for active length of the winding assembly
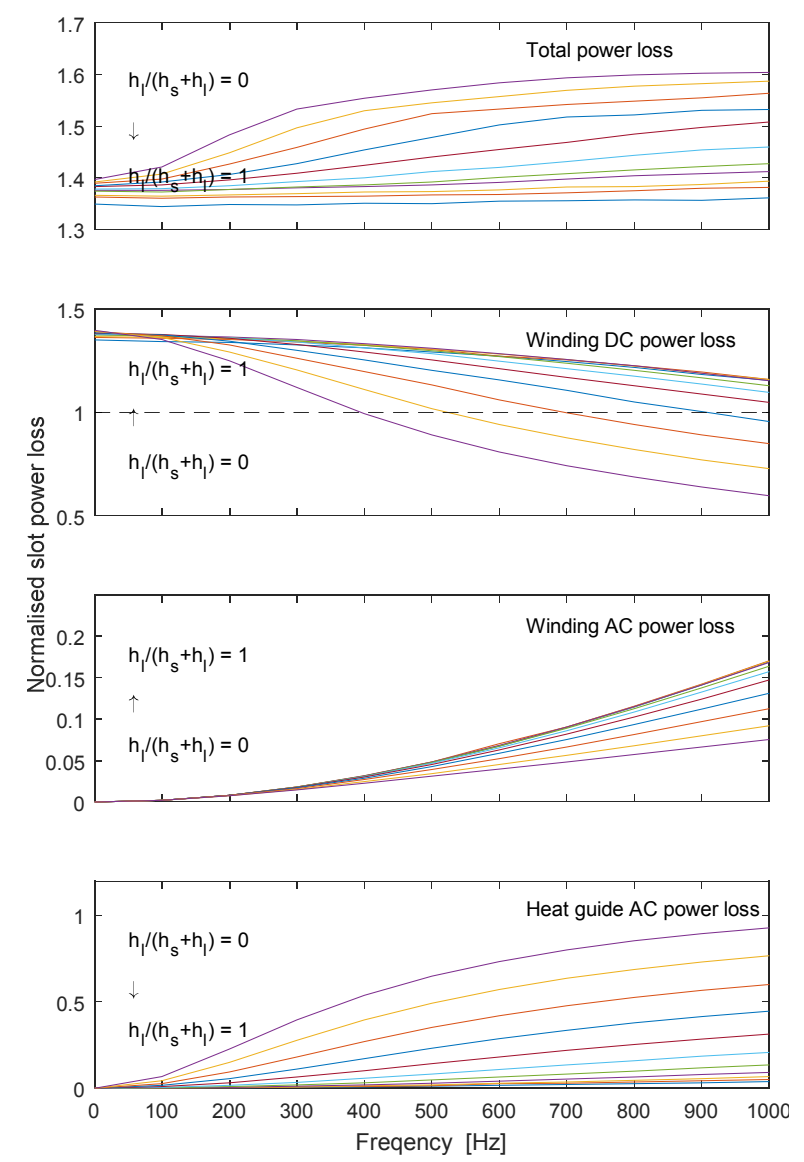

Fig. 8. Normalised power loss envelope for $180^{\circ} \mathrm{C}$ winding hot-spot temperature versus excitation frequency

Fig. 7 presents percentage improvement in dissipative heat transfer from the winding body for the analysed HG designs. The results show approximately $30 \%$ improvement as compared with the baseline design without HGs. There is a small variation among the design variants. This results from poorer axial heat transfer for HGs with reduced cross-section of the solid spine, i.e. $\left(h_{l} /\left(h_{s}+h_{l}\right)\right)$ is large. Interestingly, when analysing the results two thirds of the overall improvement in heat transfer are associated with heat path in plane of the stator-winding assembly, $x y$ plane in Fig. 6. Remaining one third is due to heat transfer along active length of the winding, $z$ axis in Fig. 6, into the heat sink. This balance might differ depending on statorwinding and $\mathrm{HG}$ design. For example if the $\mathrm{HG}$ solid spine was replaced with a HP alternative.

The initial thermal evaluation with dc winding excitation is insufficient to draw complete conclusions regarding 'optimal' HG design. Consequently, a more in-depth thermal analysis combining all ac power loss components has been carried out. Fig. 8 presents calculated winding and $\mathrm{HG}$ power losses as a function of excitation frequency. All power losses in Fig. 8 have been derived assuming $180^{\circ} \mathrm{C}$ winding hotspot temperature limit. The overall allowable power loss and its distribution has been calculated by iteratively adjusting dc winding power loss of the power loss functions discussed earlier, (3). Here, the theoretical predictions have been normalised to the baseline motorette design at dc operation. It is evident that at lower excitation frequencies all HGs perform in a similar manner with 
approximately $40 \%$ increase in dc winding power loss handling. This directly translates to higher input current magnitude by $20 \%$. The calculated data for higher frequencies revealed that HGs are also capable of enhancing current handling for that operating region, here approximately by $10 \%$. Clearly, all these would have a prominent impact on power output capability of a machine equipped with HGs.

The HGs with $\left(h_{l} /\left(h_{s}+h_{l}\right)\right)$ from 1.0 to 0.5 seem to provide the best overall performance gains. Further to these, the results show that the overall power loss, which is possible to dissipate from the motorette assembly is the highest for solidlike HG designs, i.e. $\left(h_{l} /\left(h_{s}+h_{l}\right)\right) \approx 0$. Here, approximately $60 \%$ increase in the over power loss handling has been found. This might be counterintuitive, but the generated by HGs power loss is relatively easy to dissipate as compared with the winding region. Another interesting effects is related to the winding ac loss component, which is reduced for solid-like HGs. The HG shielding effect observed here is similar to that discussed for inductor design [13].

\section{EXPERIMENTAL VALIDATION}

\section{A. Power Loss Analysis}

One of the key factors when comparing multiple hardware exemplars is the manufacture repeatability, which might affect the overall research findings. To make sure that any measured differences among the motorettes is due to alternative HG designs, all motorettes without HGs in place, were tested using the experimental setup shown in Fig. 9. The setup allows for measuring ac loss contribution in the motorette assembly by analysing frequency variation of impedance [18]. Fig. 10 shows such variation of the measured and calculated increase of the winding $\mathrm{dc}$ resistance at ac operation $\left(R_{a c} / R_{d c}\right)$ for all motorettes. The results show good correlation between the measured and calculated data. Also, the measurement spread is relatively low. All these provide a good base for the motorette tests with HGs.

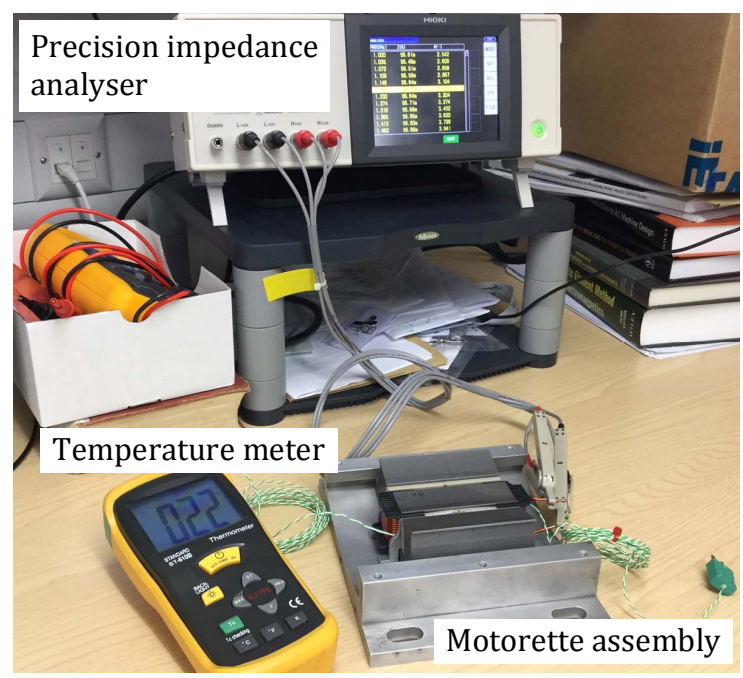

Fig. 9. Experimental setup for deriving ac loss contribution

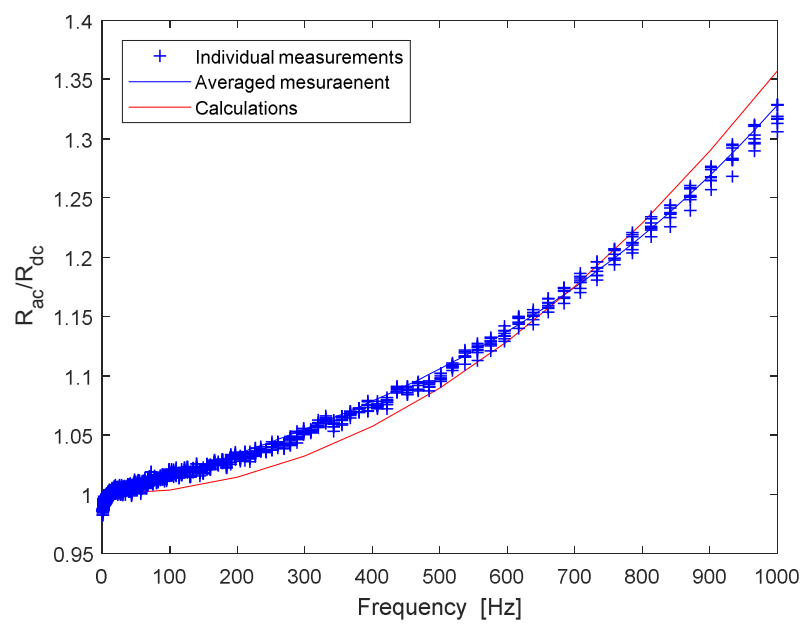

Fig. 10. Increase of winding dc resistance at ac operation versus excitation frequency at room temperature $\left(T=20^{\circ} \mathrm{C}\right)$

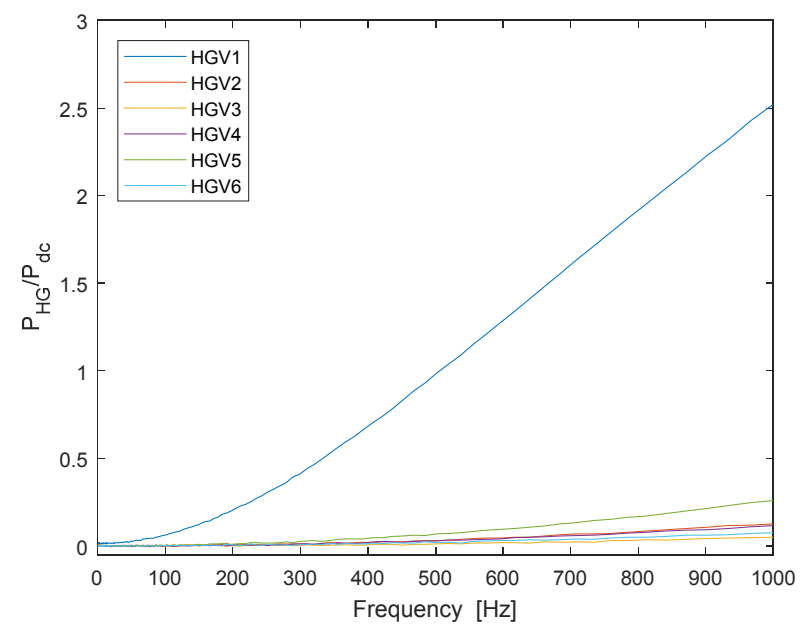

Fig. 11. Measured HG power loss contribution as a ratio of winding dc power loss versus excitation frequency at room temperature $\left(T=20^{\circ} \mathrm{C}\right)$

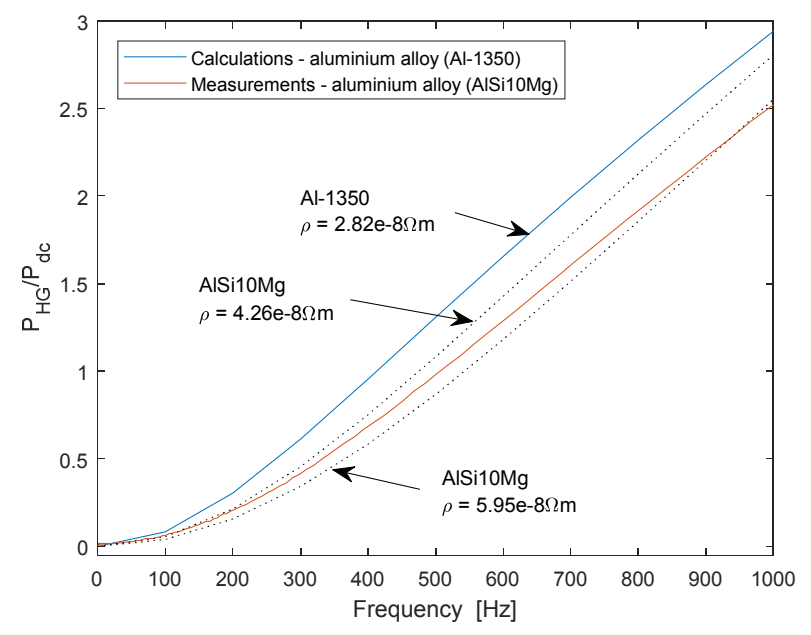

Fig. 12. Frequency variation of $\mathrm{HG}$ power loss contribution in reference to the winding ac power loss $\left(P_{H G} / P_{d c}\right)$ at room temperature $\left(T=20^{\circ} \mathrm{C}\right)$

It is important to note that the winding ac power loss contribution presented in Fig. 10 was separated from the core power loss using an experimental superposition. A motorette 
assembly with a low ac power loss winding was used to divide the power loss components [19].

Fig. 11 presents measured data from tests on the motorettes with alternative HG variants. Here, frequency variation of the HG power loss contribution normalised to dc winding power loss $\left(P_{H G} / P_{d c}\right)$ is provided. The HG power loss contribution was separated from other power loss components assuming that $R_{a c} / R_{d c}$ is identical for all analysed motorettes, i.e. shielding effect of the alternative HGs is not accounted for. As expected, the laminated HG variants, HGV2-HGV3 assure low additional power loss to the overall stator-winding power loss balance. Also, HGs with alternative lattice structures perform well, HGV4-HGV6. Here, HGV6 assures the lowest additional power loss contribution among the analysed design variants, 76 times reduction of $P_{H G} / P_{d c}$ as compared with 'solid' HG (HGV1). It is worth to remind that the presented results have been measured at room temperature, $=20^{\circ} \mathrm{C}$. At elevated temperatures the ac effects induced in HGs are expected to be considerably reduced, subject to change in electrical resistivity with temperature of the HG's material, e.g. Fig. 5.

Fig. 12 compares measured and calculated results of $P_{H G} / P_{d c}$ for HGV1. When analysing the results there is a clear discrepancy between both results. Initially, in the analysis, it was assumed that HG material has physical properties equivalent to these for aluminium alloy (Al-1350) used for electrical conductors. However, when considering additive manufacture employing SLM technique, there is a variety of aluminium alloys that could be chosen. Here, aluminium alloy (AlSil0Mg) was used [15]-[17]. It is important to note that physical properties of parts made of $\mathrm{AlSi} 10 \mathrm{Mg}$ depends on post fabrication treatment, e.g. annealing or heat treatment [15]. For example, the electrical resistivity of AlSi $10 \mathrm{Mg}$ is in range from $4.28 e-8 \Omega m$ to $5.95 e-8 \Omega m$ as compared to Al-1350 $2.82 e-8 \Omega m$ [15]. Fig. 12 shows also $P_{H G} / P_{d c}$ predictions calculated for extremities of the electrical resistivity range. The results indicate that the measured data is within the theoretically derived boundaries.

\section{B. Transient Thermal Analysis}

Thermal behaviour of the alternative motorettes considered in this investigation is another important design aspect.

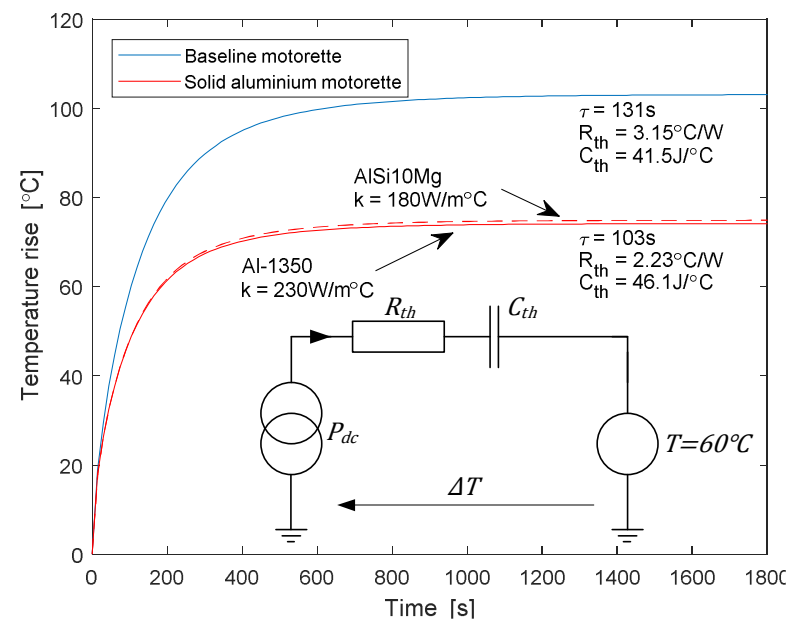

Fig. 13. Time variation of the winding hot-spot temperature
A number of theoretical predictions have been presented in the paper showing a prominent improvement in extracting heat from the winding body. It was the authors' intention to include experimentally derived thermal data in this paper. However, at the time of drafting of this manuscript the measured results were not available. Consequently, the authors decided to include a supplementary theoretical predictions illustrating transient thermal performance.

Fig. 13 show selected thermal transients for the baseline and 'solid' aluminium motorettes (HGV1). Here, time variation of the winding hot-spot temperature rise above the heat sink temperature $\left(T=60^{\circ} \mathrm{C}\right)$ is presented. In both cases, an identical dc winding excitation (a step change of fixed input winding power loss) has been introduced. Also, for simplicity, the results from 3D FEAs have been referred to a thermal equivalent circuit presented in Fig. 13. This is to give a clear comparison between the key thermal performance measures $\left(R_{t h}, C_{t h}\right)$ for the motorette variants. When analysing the results it evident that the motorette with HG provide $30 \%$ decrease in thermal resistance and $10 \%$ increase in thermal capacitance as compared with the baseline counterpart. It is worth to mention that both factors are important when considering continuous and intermediate machine operation.

Another important design aspect presented in Fig. 13 relates to physical properties of HG material. It has been shown earlier that the electrical resistivity for Al 1350 (initially assumed in the theoretical investigation) and AlSi10Mg are different. This is also the case for the thermal conductivity, which is lower for AlSi10Mg, $180 \mathrm{~W} / \mathrm{m}^{\circ} \mathrm{C}$ [17] as compared with Al-1350, $230 \mathrm{~W} / \mathrm{m}^{\circ} \mathrm{C}$. Here, the theoretical predictions suggest negligible impact of the discrepancy between thermal conductivities for the analysed aluminium alloys.

\section{Three-Phase Ac Effects}

As discussed earlier, the motorette analysis is insufficient to provide a complete quantitive information regarding power losses generated in the machine assembly. This is due to absence of the winding neighbouring phases and rotor PM magnetic flux among others. These effects however, would require the complete machine to be properly assessed experimentally.

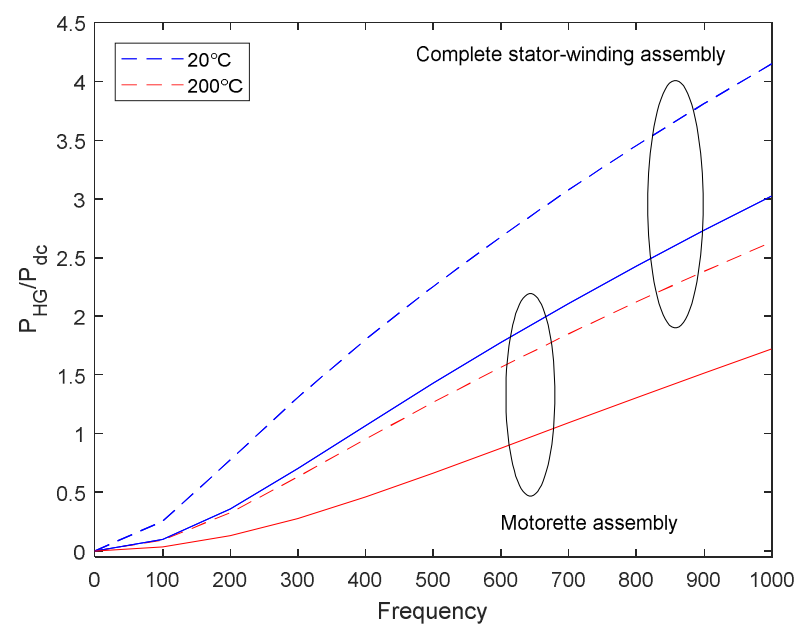

Fig. 14. Frequency variation of $\mathrm{HG}$ power loss contribution in reference to the winding dc power loss $\left(P_{H G} / P_{d c}\right)$ for 'solid' aluminium motorette 


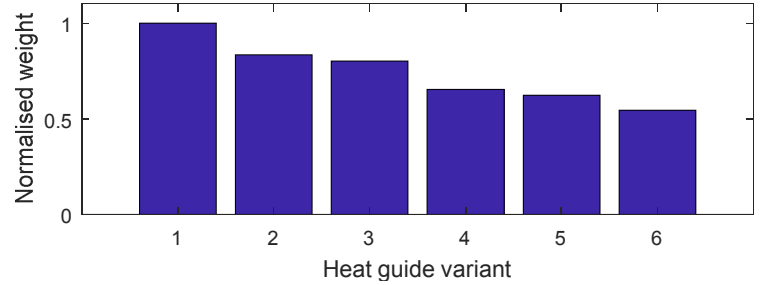

Fig. 15. Normalised weight of the alternative HG designs

In this analysis a simplified theoretical illustration is used instead. Fig. 14 presents results from 3D FEAs of the HG's power loss contribution for both motorette and complete statorwinding assemblies. Here, motorette with solid $\mathrm{HG}$ is considered. As expected, the magnetic flux leakage between neighbouring phases has a detrimental effect on the HG performance. This results in 36\% increase of the power loss generated in the HG. Although, the increase might appear to be considerable, it was derived for the worst case scenario, i.e. HGV1 with Al-1350. Thus, the overall power loss for alternative HG designs (HGV2-HGV6) and material (AlSi10Mg) is expected to remain relatively small.

\section{OBSERVATIONS AND CONCLUSIONS}

This feasibility study has shown that passive HGs can be designed and manufactured to assure enhanced heat transfer from the winding body and insignificant additional power loss to the overall system (complete machine assembly). The initial results suggest approximately $40 \%$ increase in input power handling at low low-frequency operation and $20 \%$ improvement at high-frequency for the analysed case study. The theoretical predictions have been partially validated experimentally showing good correlation with measured data. It has be shown that material properties of the HG hardware differ from the initially assumed material data. In particular, higher electrical resistivity of aluminium alloys commonly used in SLM, like $\mathrm{AlSi} 10 \mathrm{Mg}$, assures reduced HG power loss. The material thermal conductivity is also affected, but here with insignificant impact on the heat transfer capability. The additive manufacturing employed in fabrication of the alternative HGs enabled light-weight, low-power loss and 'good' thermal conductivity design solutions. For examples, introduction of the HGs to the stator-winding assembly contributes 3\% to $4 \%$ additional weight (epoxy impregnated stator-winding assembly with no housing is considered here). Fig. 15 shows how SLM helped in reducing HGs weight, with $47 \%$ reduction in weight for HGV6 as compared to solid HG constructions (HGV1). The proposed passive heat extraction approach has a good potential. However, more experimental work is required to fully validate and understand all $\mathrm{HG}$ performance measures. In particular, HG thermal behaviour and material physical properties will be investigated by the authors as a continuation of this proof of concept study.

\section{ACKNOWLEDGMENT}

The authors wish to thank Advanced Propulsion Centre (APC) UK for supporting this research.

\section{REFERENCES}

[1] D. A. Reay, P. A. Kew, R. McGlen, "Heat Pipes: Theory, Design and Applications," Elsevier, 2013.

[2] T. Hasset, M. Hodowanec, "Electric Motor with Heat Pipes," United States Patent, US 7569955 B2, 2009.

[3] M. Bradford, "The Application of Heat Pipes to Cooling Rotating Electrical Machines," IET International Conference on Electrical Machines and Drives, pp. 145 - 149, 1989.

[4] M. Popescu, D. A. Staton, A. Boglietti, A. Cavagnino, D. Hawkons, J. Goss, "Modern Heat Extraction Systems for Power Traction Machines A Review," IEEE Transactions on Industry Applications, vol. 52, no. 3, pp. $2167-2175$, May/June 2016.

[5] S. Ayat, R. Wrobel, J. Goss, D. Drury, "Experiment Informed Methodology for Thermal Design of PM Machines,” IEEE International Conference on Ecological Vehicles and Renewables Energies, pp. 1 - 7, 2016.

[6] J. Godbehere, R. Wrobel, D. Drury, P. H. Mellor, "Experimentally Calibrated Thermal Stator Modelling of AC Machines for Short-Duty Transient Operation," IEEE Transactions on Industry Applications, vol. 53, no. 4, pp. 3457 - 3466, July/August 2017.

[7] R. Wrobel, D. E. Salt, A. Griffo, N. Simpson, P. H. Mellor, "Derivation and Scaling of AC Copper Loss in Thermal Modelling of Electrical Machines," IEEE Transactions on Industrial Electronics, vol. 61, no. 8, pp. 4412 - 4420, August 2014.

[8] R. Wrobel, N. Simpson, P. H. Mellor, J. Goss, D. A. Staton, "Design od a Brushless PM Starter Generator for Low-Cost Manufacture and HighAspect-Ratio Mechanical Space Envelope," IEEE Transactions on Industry Applications, vol. 53, no. 2, pp. 1038 - 1048, March/April 2017.

[9] R. Wrobel, D. Staton, R. Lock, J. Booker, D. Drury, "Winding Design for Low-Cost Manufacture in Application to Fixed-Speed PM Generator," IEEE Transactions on Industry Applications, vol. 51, no. 5, pp. 3773 3782, September/October 2015.

[10] R. Wrobel, P. H. Mellor, D. Holliday, "Thermal Modelling of Segmented Stator Winding Design," IEEE Transactions on Industry Applications, vol. 47, no. 5, pp. 2023 - 2030, September/October 2011.

[11] J. Goss, M. Popescu, D. Staton, R. Wrobel, J. Yon, P. Mellor, “A Comparision between Maxium Torque/Ampere Efficiency Control Strategies in IPM Synchronous Machines," IEEE Energy Conversion Congress and Exposition, pp. 2403 - 2410, 2014.

[12] N. Simpson, R. Wrobel, P. H. Mellor, "Estimation of Equivalent Thermal Parameters of Impregnated Electrical Windings," IEEE Transactions on Industry Applications, vol. 49, no. 6, pp. 2505 - 2515, November/ December 2013.

[13] J. Fletcher, B. Williams, M. Mahmoud, "Airgap Fringing Fux Reduction in Inductors Using Open-Circuit Copper Screens," IEE Proceedings Electric Power Applications, vol. 152, no. 4, pp. 990 - 996, July 2005.

[14] R. Camilleri, D. A. Howey, M. D. McCulloch,"Experimental Investigation of the Thermal Contact Resistance in Shrink Fit Assemblies with Relevance to Electrical Machines," IET International Conference on Power Electronics, Machines and Drives, pp. 1 - 9, 2014.

[15] C. Silbernagel, I. Ashcroft, P. Dickens, M. Galea, "Electrical Resistivity of Additevely Manufactured AlSi10Mg for Use in Electric Motors," Elsevier, Additive Manufacturing, vol. 21, pp. 395 - 403, May 2018.

[16] X. Zhao, B. Song, W. Fan, Y. Zhang, Y. Shi, "Selective Laser Melting of Carbon/AlSi10Mg Composities: Microstructure, Mechanical and Electronical Properties," Elsevire, Journal of Alloys and Compounds, vol. 665, pp. 271 - 281, April 2016.

[17] Reinshaw Material Data Sheet, "AlSi10Mg-0403 Powder for Additive Manufacturing,” 2015

[18] R. P. Wojda, M. K. Kazimierczuk, "Winding Resistance of Litz-Wire and Multi-Strand Inductors," IET Power Electronics, vol. 5, pp. 257-268, 2012.

[19] P. Mellor, R. Wrobel, N.Simpson, "Ac Loss in High Frequency Electrical Machine Widimgs Formed from Large Section Conductrors," IEEE Energy Conversion Congress and Exposition, pp. 5563 - 5570, 2014. 